\title{
QRS pattern and improvement in right and left ventricular function after cardiac resynchronization therapy: a radionuclide study
}

\author{
Giulia Domenichini ${ }^{1,2}$, Haran Burri ${ }^{2}$, Cinzia Valzania ${ }^{1}$, Gilberto Gavaruzzi ${ }^{3}$, Francesco Fallani ${ }^{1}$, Mauro Biffi ${ }^{1}$, \\ Henri Sunthorn², Igor Diemberger ${ }^{1}$, Cristian Martignani ${ }^{1}$, Huberdine Foulkes ${ }^{2}$, Eric Fleury ${ }^{2}$ and Giuseppe Boriani ${ }^{*}$
}

\begin{abstract}
Background: Predicting response to cardiac resynchronization therapy $(C R T)$ remains a challenge. We evaluated the role of baseline QRS pattern to predict response in terms of improvement in biventricular ejection fraction (EF).

Methods: Consecutive patients (pts) undergoing CRT implantation underwent radionuclide angiography at baseline and at mid-term follow-up. The relationship between baseline QRS pattern and mechanical dyssynchrony using phase analysis was evaluated. Changes in left and right ventricular EF (LVEF and RVEF) were analyzed with regard to baseline QRS pattern.

Results: We enrolled 56 pts, 32 with left bundle branch block (LBBB), 4 with right bundle branch block (RBBB) and 20 with non-specific intraventricular conduction disturbance (IVCD). A total of 48 pts completed follow-up. LBBB pts had significantly greater improvement in LVEF compared to RBBB or non-specific IVCD pts $(+9.6 \pm 10.9 \%$ vs. $+2.6 \pm$ $7.6 \%, p=0.003$ ). Response (defined as $\geq 5 \%$ increase in LVEF) was observed in $68 \%$ of LBBB vs. $24 \%$ of non-specific IVCD pts $(p=0.006)$. None of the RBBB pts were responders. RVEF was significantly improved in $L B B B(+5.0 \pm 9.0 \%$, $p=0.007)$, but not in non-specific IVCD and RBBB pts $(+0.4 \pm 5.8 \%, p=0.76)$. At multivariate analysis, LBBB was the only predictor of LVEF response (OR, 7.45; 95\% Cl 1.80-30.94; $\mathrm{p}=0.006)$, but not QRS duration or extent of mechanical dyssynchrony.
\end{abstract}

Conclusions: Presence of a LBBB is a marker of a positive response to CRT in terms of biventricular improvement. Pts with non-LBBB pattern show significantly less benefit from CRT than those with LBBB.

Keywords: Cardiac resynchronization therapy, Left ventricular ejection fraction, Right ventricular ejection fraction, Dyssynchrony, Nuclear angiography, QRS morphology

\section{Background}

Cardiac resynchronization therapy (CRT) reduces morbidity and mortality in patients (pts) with congestive heart failure [1-5] improving clinical status [1-3] and favoring ventricular reverse remodeling [2,5-7]. However clinical and/or echocardiographic response is present in only $50-70 \%$ of CRT pts [3,8], suggesting that the link between standard criteria for CRT and expected response is often weak. Several parameters of electrical and mechanical dyssynchrony have been proposed to

\footnotetext{
* Correspondence: giuseppe.boriani@unibo.it

${ }^{1}$ Institute of Cardiology, University of Bologna, Via Massarenti 9, Bologna 40138, Italy

Full list of author information is available at the end of the article
}

improve pt selection, even though QRS duration is currently the only recommended parameter $[9,10]$. In CRT pts a baseline left bundle branch block (LBBB) has been demonstrated to be associated with a more favorable prognosis in terms of freedom from death or major cardiovascular events, and with a more left ventricular (LV) reverse remodeling compared to a baseline right bundle branch block (RBBB) [11,12]. Likewise in the RAFT trial [13] LBBB pts showed more benefit from CRT in terms of death or hospitalization for heart failure compared to pts with RBBB, non-specific intraventricular conduction disturbance (IVCD) or paced QRS at baseline. Furthermore, in a secondary analysis of the MADIT-CRT trial [14] a significant reduction in the risk of heart failure or

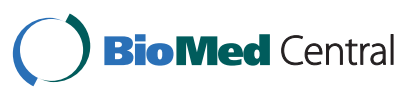


death has been reported in LBBB pts within the CRT plus defibrillator (CRT-D) group. However, if the role of baseline LBBB in terms of prognosis and LV function during CRT seems to be established, there is lack of data regarding its effects on right ventricular (RV) function. Likewise, few data are available on the impact of baseline RBBB or non-specific IVCD patterns on biventricular function during CRT.

In our study we investigated the relationship between baseline QRS pattern and biventricular mechanical dyssynchrony and we evaluated the role of baseline QRS morphology to predict CRT response in terms of improvement in biventricular ejection fraction (EF). Radionuclide angiography with phase analysis was used to evaluate mechanical dyssynchrony and to measure LVEF and RVEF.

\section{Methods \\ Patient population}

We enrolled 28 pts undergoing CRT device implantation at the Cardiology Institute, University Hospital of Bologna (inclusion period: January 2007- July 2009), and 28 pts implanted at the Cardiology Service, University Hospital of Geneva (inclusion period: September 2002December 2004). According to current guidelines [9], pts had to be in New York Heart Association (NYHA) class III or IV, with LVEF $\leq 35 \%$ and with QRS duration $\geq 120 \mathrm{~ms}$. All pts were in sinus rhythm at implantation and under optimal pharmacological treatment.

A control group of 25 subjects without cardiovascular disease and with normal electrocardiogram (ECG), matched for age and sex with the study group, was evaluated to define the cut-off of inter and intraventricular dyssynchrony of phase analysis parameters.

The local institutional Ethics Committees (Ethics Committee of the S.Orsola-Malpighi Hospital of Bologna and Clinical Ethics Committee of the Geneva University Hospitals) approved the study protocol, and all patients provided a written informed consent for participation.

\section{Device implantation}

All device leads were placed transvenously. The RV lead was positioned at the mid-septum or at the apex at the discretion of the implanting physician. The LV lead was positioned via the coronary sinus, targetting lateral or posterolateral veins. An echocardiographic-guided optimization of CRT programming was performed after implantation according to conventional clinical practice.

\section{Baseline electrocardiograms}

A surface 12-lead ECG was recorded before implantation at speed of $25 \mathrm{~mm} / \mathrm{s}$ and at $10 \mathrm{~mm} / \mathrm{mV}$ gain. The QRS interval was measured from its first deflection to its end at the widest QRS complex. The QRS patterns were classified as $\mathrm{LBBB}$ or RBBB or non-specific IVCD according to the "AHA/ACCF/HRS Recommendations for the Standardization and Interpretation of the Electrocardiogram" [15]. Left axis deviation was defined as a QRS axis leftward of $-30^{\circ}$ [15].

\section{Radionuclide angiography}

LVEF and RVEF were measured by radionuclide angiography at baseline, during spontaneous rhythm, and at mid-term follow-up (between 3 and 6 month from device implantation), during biventricular pacing. The response to CRT was defined by an increase in LVEF of $\geq 5 \%$ at follow-up end [16]. Radionuclide angiography was performed as previously described $[17,18]$, using a gamma camera Prism 2000 XP- Philips in Bologna and a gamma camera ADAC-Philips in Geneva. A blood sample was drawn to label red blood cells with $1 \mathrm{GBq}$ of $99 \mathrm{mTechnetium}$. The ECG was monitored continuously for R-wave gating, with elimination of extrasystolic and post-extrasystolic cycles. Multigated equilibrium blood pool planar scintigrams at 32 frames/cycle (200$250 \mathrm{Kcounts} /$ frame in a $128 \times 128$ matrix) were acquired until the number of counts was at least $6 \times$ $10^{6}$ in the "best septal separation" left anterior oblique view that provided optimal RV and LV discrimination. A background-corrected, time-activity curve was constructed by a semi-automated edge-detection method with a variable region of interest, verified visually and modified manually if necessary. LVEF and RVEF were computed on the basis of relative end-diastolic and endsystolic counts.

Inter- and intraventricular dyssynchrony were obtained by phase analysis, as previously reported [19]. The images acquired for measuring LVEF and RVEF were digitally processed to display the "phase" of each pixel overlying the ECG-gated equilibrium blood pool. The computer assigned a phase angle (between 0 and $360^{\circ}$ ) to each pixel of the image. A phase histogram was constructed, corresponding to the sequence of ventricular contraction during the cardiac cycle, with color codes corresponding to different regions of the ventricles. Each ventricle was analyzed separately, with calculation of the mean and standard deviation (SD) of the phase histogram. Interventricular delay was assessed by the absolute difference between the mean phase angles of each ventricle, whereas intraventricular delay was represented by the SD of the phase histogram for that ventricle. Both inter and intraventricular delays were expressed in angles $\left(^{\circ}\right)$.

\section{Statistical analysis}

Statistical analyses were performed using SPSS software (SPSS Inc., Chicago, IL, USA). Continuous variables showing normal distribution according to Kolmogorov- 
Smirnov test were compared using paired and unpaired Student's t-tests for related and unrelated groups, respectively. Data showing non-Gaussian distribution were processed using the Mann-Whitney test. Correlations between quantitative variables were examined using Pearson's test. Fisher's exact test was used for evaluating categorical variables. Logistic regression analysis was performed to evaluate the relationship between baseline clinical parameters and CRT response. Values were expressed as mean \pm SD or median and interquartile range (IQR) in case of non-Gaussian distribution. Odds ratios (OR) were presented with $95 \%$ confidence intervals (CIs). A P-value of less than 0.05 was considered statistically significant.

\section{Results}

We enrolled a total of 56 pts, 42 males, age $66 \pm 11$ years (see Table 1). Thirty-four pts received a CRT-D device. LV lead position was lateral/posterolateral in 49 pts (88\%) and anterolateral in 7 pts (12\%); RV lead was positioned at the mid-septum in 11 pts $(20 \%)$. There were no significant differences between groups as

Table 1 Demographics of the patient population

\begin{tabular}{|c|c|}
\hline Patient demographics & \\
\hline Age (years) & $66 \pm 11$ \\
\hline Males & $42(75 \%)$ \\
\hline \multicolumn{2}{|l|}{ Aetiology of heart failure } \\
\hline Ischaemic & $22(39 \%)$ \\
\hline Non-ischaemic & $34(61 \%)$ \\
\hline \multicolumn{2}{|l|}{ NYHA class } \\
\hline III & $49(88 \%)$ \\
\hline IV & 7 (12\%) \\
\hline Paroxysmal AF & $5(9 \%)$ \\
\hline Hypertension & $30(54 \%)$ \\
\hline Diabetes & 19 (34\%) \\
\hline Chronic kidney disease & $14(25 \%)$ \\
\hline \multicolumn{2}{|l|}{ QRS morphology } \\
\hline LBBB & $32(57 \%)$ \\
\hline RBBB & $4(7 \%)$ \\
\hline Non-specific IVCD & $20(36 \%)$ \\
\hline QRS duration (ms) & 140 (120-160) \\
\hline $\mathrm{QRS} \geq 150 \mathrm{~ms}$ & $27(48 \%)$ \\
\hline LVEF (\%) & $22 \pm 6$ \\
\hline RVEF (\%) & $36 \pm 10$ \\
\hline \multicolumn{2}{|l|}{ Traitement } \\
\hline ACE-I/ARBS & $52(93 \%)$ \\
\hline Beta-blockers & 39 (70\%) \\
\hline Diuretics & $50(89 \%)$ \\
\hline
\end{tabular}

NYHA class, New York Heart Association class; AF, atrial fibrillation; LBBB, left bundle branch block; RBBB, right bundle branch block; IVCD, intraventricular conduction disturbance; LVEF, left ventricular ejection fraction; RVEF, right ventricular ejection fraction; ACE-Is, angiotensin-converting enzyme inhibitors; ARBs, angiotensin II receptor blockers regards the position of LV and RV leads. A total of 48 pts completed follow-up after a median of 5.5 (3.5-7.1) months. Two pts (1 LBBB and 1 RBBB) died for noncardiac causes and 6 pts dropped out (3 LBBB and 3 non-specific IVCD).

\section{Baseline QRS pattern and mechanical dyssynchrony}

In the control group (age $63 \pm 4$ years, 13 males, LVEF $62 \pm 6 \%$, RVEF $48 \pm 5 \%$ ), intraventricular delay for the left ventricle was $10.9^{\circ}\left(8.2-16.1^{\circ}\right)$ and $16.9^{\circ}\left(12.3-19.6^{\circ}\right)$ for the right ventricle. The interventricular delay was $5.0^{\circ}\left(3.0-11.5^{\circ}\right)$. Values greater than the 95 th percentile of the distribution curve (after rounding to a multiple of $5^{\circ}$ ) were considered as dyssynchronous. Therefore, we defined intraventricular dyssynchrony as SD values $>20^{\circ}$ for the LV phase and as SD values $>25^{\circ}$ for the RV phase. Interventricular dyssynchrony was defined as values $>15^{\circ}$.

Table 2 shows the baseline clinical characteristics of the study population according to QRS pattern. The QRS duration was significantly longer in the LBBB group compared to the non-specific IVCD group. Furthermore, non-ischemic aetiology of heart failure was prevalent in the LBBB pts and male sex was more represented in the non-specific IVCD group.

The comparisons of mechanical dyssynchrony according to QRS pattern and QRS duration are shown in Table 3. The differences in dyssynchrony between the groups did not reach statistical significance, although

Table 2 Baseline characteristics according to QRS pattern

\begin{tabular}{|c|c|c|c|}
\hline & $\begin{array}{c}\text { LBBB } \\
(n=32)\end{array}$ & $\begin{array}{l}\text { RBBB } \\
(n=4)\end{array}$ & $\begin{array}{c}\text { Non-specific } \\
\text { IVCD } \\
(n=20) \\
\end{array}$ \\
\hline Age (years) & $66 \pm 11$ & $65 \pm 9$ & $67 \pm 10$ \\
\hline Males & $21(66 \%)$ & $2(50 \%)$ & $19(95 \%)^{*}$ \\
\hline \multicolumn{4}{|l|}{$\begin{array}{l}\text { Aetiology of heart } \\
\text { failure }\end{array}$} \\
\hline Ischaemic & $9(28 \%)$ & $3(75 \%)$ & $10(50 \%)$ \\
\hline Non-ischaemic & $23(72 \%)$ & $1(25 \%)$ & $10(50 \%)$ \\
\hline \multicolumn{4}{|l|}{ NYHA class } \\
\hline III & $28(88 \%)$ & $4(100 \%)$ & 17 (85\%) \\
\hline IV & $4(12 \%)$ & $0(0 \%)$ & $3(15 \%)$ \\
\hline QRS duration (ms) & $\begin{array}{c}160(140- \\
180)\end{array}$ & $\begin{array}{c}140(125- \\
170)\end{array}$ & $120(120-130)^{5}$ \\
\hline $\mathrm{QRS} \geq 150 \mathrm{~ms}$ & $22(69 \%)$ & $1(25 \%)$ & $4(20 \%)^{\dagger}$ \\
\hline LEFT axis & $15(47 \%)$ & $3(75 \%)$ & $10(50 \%)$ \\
\hline LVEF (\%) & $23 \pm 6$ & $25 \pm 6$ & $21 \pm 7$ \\
\hline RVEF (\%) & $37 \pm 11$ & $38 \pm 9$ & $34 \pm 8$ \\
\hline
\end{tabular}

${ }^{*} p=0.018$ vs LBBB; ${ }^{\S} p<0.001$ vs LBBB; ${ }^{\dagger} p=0.001$ vs LBBB

LBBB, left bundle branch block; RBBB, right bundle branch block; IVCD, intraventricular conduction disturbance; NYHA class, New York Heart Association class; LVEF, left ventricular ejection fraction; RVEF, right ventricular ejection fraction 
Table 3 Comparison of mechanical dyssynchrony according to QRS pattern and QRS duration

\begin{tabular}{lcccccc}
\hline & $\begin{array}{c}\text { Control group } \\
(\boldsymbol{n}=\mathbf{2 5})\end{array}$ & $\begin{array}{c}\text { LBBB } \\
(\boldsymbol{n}=\mathbf{3 2})\end{array}$ & $\begin{array}{c}\text { RBBB } \\
(\boldsymbol{n}=\mathbf{4})\end{array}$ & $\begin{array}{c}\text { Non-specific IVCD } \\
(\boldsymbol{n}=\mathbf{2 0})\end{array}$ & $\begin{array}{c}\text { QRS }<\mathbf{1 5 0} \text { ms } \\
(\boldsymbol{n}=\mathbf{2 9})\end{array}$ & $\begin{array}{c}\text { QRS } \geq \mathbf{1 5 0} \text { ms } \\
(\boldsymbol{n}=\mathbf{2 7})\end{array}$ \\
\hline SD of LV mean phase $\left(^{\circ}\right)$ & $10.9(8.2-16.1)$ & $42.3(24.7-77.9)^{*}$ & $35.4(28.8-39.2)^{*}$ & $43.4(36.0-59.6)^{*}$ & $36.9(27.0-50.4)^{*}$ & $48.4(29.5-78.1)^{*}$ \\
SD of RV mean phase $\left(^{\circ}\right)$ & $16.9(12.3-19.6)$ & $27.2(18.8-38.8)^{*}$ & $20.4(11.9-34.9)$ & $25.5(17.8-36.0)^{*}$ & $26.1(18.8-35.9)^{*}$ & $25.5(17.4-39.8)^{*}$ \\
Interventricular delay $\left(^{\circ}\right)$ & $5.0(3.0-11.5)$ & $21.0(8.5-34.8)^{*}$ & $17.5(4.0-40.0)$ & $14.0(6.5-25.3)^{*}$ & $19.0(6.5-28.0)^{*}$ & $21.0(8.0-28.0)^{*}$ \\
\hline Intra LV dyssynchrony & & $28(88 \%)$ & $4(100 \%)$ & $20(100 \%)$ & $26(90 \%)$ & $25(93 \%)$ \\
Intra RV dyssynchrony & & $18(56 \%)$ & $2(50 \%)$ & $10(50 \%)$ & $16(55 \%)$ & $14(52 \%)$ \\
Interventricular dyssynchrony & & $22(69 \%)$ & $2(50 \%)$ & $10(50 \%)$ & $16(55 \%)$ & $17(63 \%)$ \\
\hline
\end{tabular}

${ }^{*} p<0.01$ vs control group

LBBB, left bundle branch block; RBBB, right bundle branch block; IVCD, intraventricular conduction disturbance; SD, standard deviation; LV, left ventricular; RV, right ventricular

comparisons are limited by small sample size and data dispersion.

\section{Baseline QRS pattern and changes in biventricular} ejection fraction at follow-up

CRT response was observed in $68 \%$ of LBBB vs. $24 \%$ of non-specific IVCD pts $(p=0.006)$. None of the RBBB pts were responders. Pts with LBBB had significantly greater improvement in LVEF compared to those with RBBB and non-specific IVCD $(+9.6 \pm 10.9 \%$ vs. $+2.6 \pm$ $7.6 \%, \mathrm{p}=0.003$ ) (see Figure 1). RVEF was significantly improved in LBBB pts $(+5.0 \pm 9.0 \%, \mathrm{p}=0.007)$, but not in non-specific IVCD and RBBB pts $(+0.4 \pm 5.8 \%, \mathrm{p}=$ 0.76 ) (see Figure 2). No significant correlation was found between increase in LVEF and increase in RVEF in LBBB pts $(r=0.22, \mathrm{p}=0.25)$.

\section{Reproducibility of radionuclide angiography}

LVEF and RVEF and LV and RV mean phase angle reproducibility were assessed in independent readings, done by the same operator, of the same nuclear examination.
We found that the difference between two independent measurements, expressed in absolute terms, was $0.49 \pm 2.47 \%$ (centre A) and $0.56 \pm 1.58 \%$ (centre B) for LVEF; $0.10 \pm 3.5 \%$ (centre A) and $0.65 \pm 6.1 \%$ (center B) for RVEF; $2.20 \pm 8.84^{\circ}$ (centre A) and $3.39 \pm 4.63^{\circ}$ (centre B) for LV mean phase angle; $2.01 \pm 7.31^{\circ}$ (centre A) and $2.28 \pm 9.91^{\circ}$ (centre B) for RV mean phase angle. These data indicate that the differences between two independent measurements of RVEF or LVEF or mean phase angles were negligible in absolute terms. Furthermore no significant differences were found between the two centres.

\section{Baseline clinical characteristics predicting response to CRT}

Baseline LBBB showed a significantly higher prevalence in CRT responders compared to RBBB and non-specific IVCD ( $\mathrm{p}=0.001)$ (see Table 4). Furthermore, CRT responders tended to have greater QRS duration and also tended to have more frequently cardiomyopathy of non-ischemic origin, though significant differences were not present. Finally, mechanical dyssynchrony

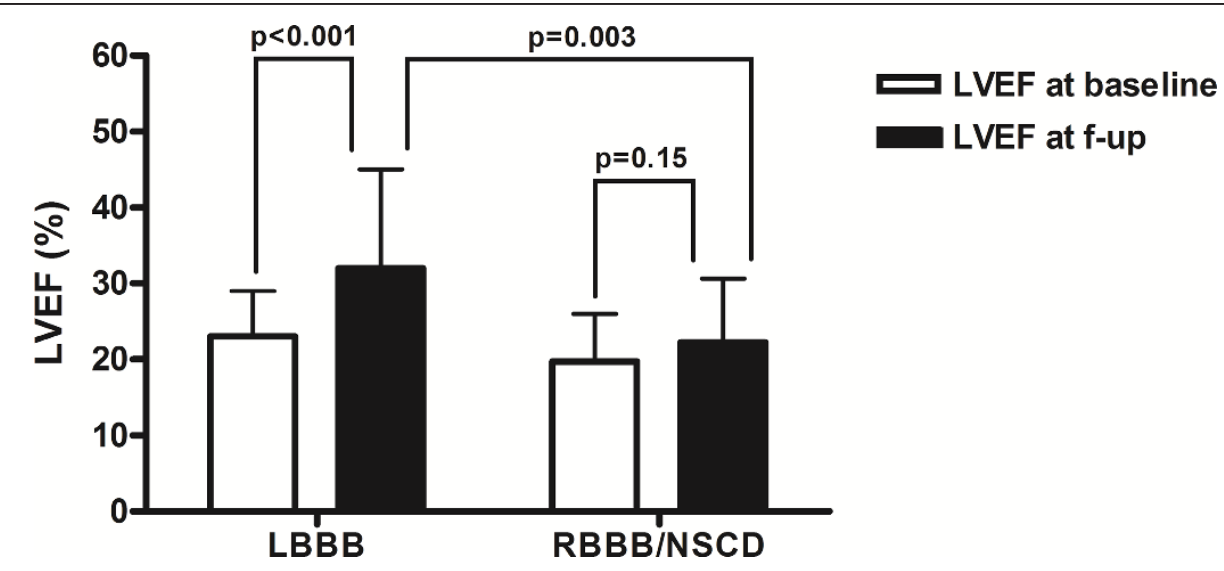

Figure 1 Baseline QRS pattern and changes in left ventricular ejection fraction (LVEF) at follow-up. LBBB, left bundle branch block; RBBB, right bundle branch block; NSCD, non-specific intraventricular conduction disturbance. 


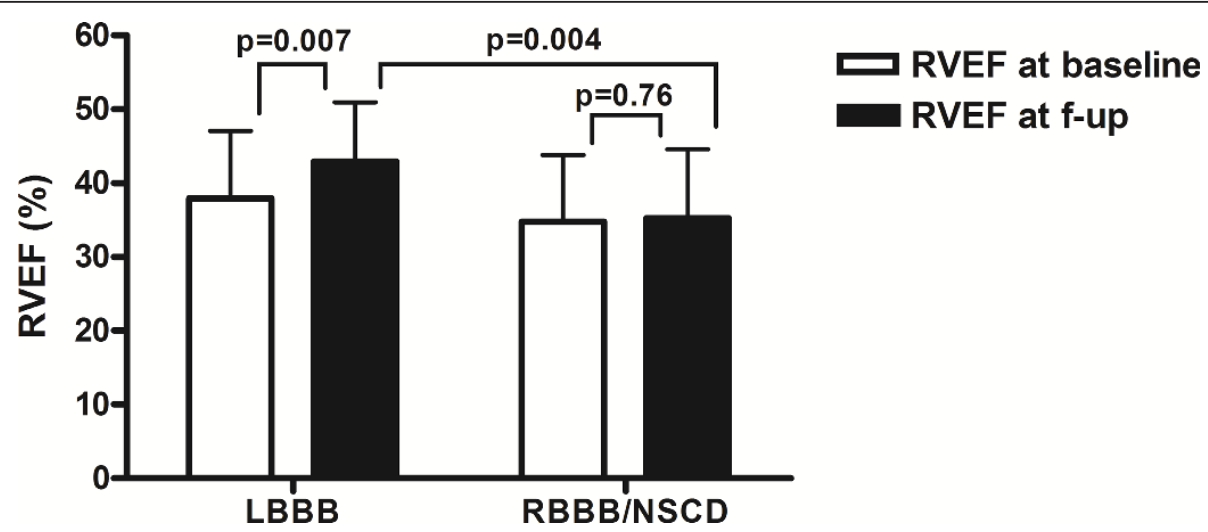

Figure 2 Baseline QRS pattern and changes in right ventricular ejection fraction (RVEF) at follow-up. LBBB, left bundle branch block; RBBB, right bundle branch block; NSCD, non-specific intraventricular conduction disturbance.

Table 4 Baseline clinical characteristics according to CRT response at follow-up

\begin{tabular}{|c|c|c|c|}
\hline & $\begin{array}{l}\text { Responders } \\
(n=23)\end{array}$ & $\begin{array}{c}\text { Non } \\
\text { Responders } \\
(n=25)\end{array}$ & $p$ \\
\hline Age (years) & $67 \pm 11$ & $65 \pm 11$ & 0.64 \\
\hline Males & $15(65 \%)$ & $21(84 \%)$ & 0.19 \\
\hline \multicolumn{4}{|l|}{ Aetiology of heart failure } \\
\hline Ischaemic & $6(26 \%)$ & $11(44 \%)$ & 0.24 \\
\hline Non-ischaemic & $17(74 \%)$ & $14(56 \%)$ & \\
\hline \multicolumn{4}{|l|}{ NYHA class } \\
\hline III & $21(87 \%)$ & $23(92 \%)$ & 0.67 \\
\hline IV & $3(13 \%)$ & $2(8 \%)$ & \\
\hline QRS duration (ms) & $150(120-160)$ & $140(120-180)$ & 0.77 \\
\hline $\mathrm{QRS} \geq 150 \mathrm{~ms}$ & $12(52 \%)$ & $12(48 \%)$ & 0.99 \\
\hline LEFT axis & $11(48 \%)$ & $14(56 \%)$ & 0.77 \\
\hline \multicolumn{4}{|l|}{ QRS morphology } \\
\hline LBBB & $19(83 \%)$ & $9(36 \%)$ & $0.001^{*}$ \\
\hline RBBB & $0(0 \%)$ & $3(12 \%)$ & $0.24^{\S}$ \\
\hline Non-specific IVCD & $4(17 \%)$ & $13(52 \%)$ & $0.017^{\dagger}$ \\
\hline LVEF (\%) & $23 \pm 5$ & $20 \pm 6$ & 0.05 \\
\hline RVEF (\%) & $37 \pm 8$ & $36 \pm 10$ & 0.74 \\
\hline SD of LV mean phase $\left(^{\circ}\right)$ & $\begin{array}{l}43.0(24.0- \\
73.0)\end{array}$ & $43.0(35.5-64.5)$ & 0.48 \\
\hline SD of RV mean phase $\left(^{\circ}\right)$ & $\begin{array}{l}28.0(19.0- \\
40.0)\end{array}$ & $26.0(17.5-36.5)$ & 0.40 \\
\hline Interventricular delay $\left(^{\circ}\right)$ & $21.0(8.0-38.0)$ & $20.0(8.5-27.5)$ & 0.56 \\
\hline Intra LV dyssynchrony & $20(87 \%)$ & $24(96 \%)$ & 0.34 \\
\hline Intra RV dyssynchrony & $16(70 \%)$ & $13(52 \%)$ & 0.25 \\
\hline $\begin{array}{l}\text { Interventricular } \\
\text { dyssynchrony }\end{array}$ & $16(70 \%)$ & $15(60 \%)$ & 0.56 \\
\hline
\end{tabular}

*LBBB vs. RBBB and non-specific IVCD; \$RBBB vs. LBBB and non-specific IVCD; † non-specific IVCD vs. LBBB and RBBB.

NYHA class, New York Heart Association class; LBBB, left bundle branch block; RBBB, right bundle branch block; IVCD, intraventricular conduction disturbance; LVEF, left ventricular ejection fraction; RVEF, right ventricular ejection fraction; SD, standard deviation; $\mathrm{LV}$, left ventricular; RV, right ventricular parameters did not differ significantly between the two groups. At multivariate analysis, LBBB was the only predictor of CRT response (OR, 7.45; 95\% CI 1.80-30.94; p $=0.006)$ (see Table 5).

\section{Discussion}

The main findings of our study may be summarized as follows: 1. A baseline LBBB morphology is a marker of a positive response to CRT in terms of improvement not only in LVEF but also in RVEF; 2. Pts with a baseline $\mathrm{RBBB}$ or an IVCD pattern seem to derive less benefit from CRT compared to those with LBBB.

Our study included pts with both non-ischemic as well as ischemic cardiomyopathy and assessed the response to CRT in terms of both right and left ventricular function. In the literature limited attention has been paid to RV function, and this can be easily explained by the limitation of echocardiographic approaches. In pts with idiopathic dilated cardiomyopathy, Fauchier et al. [20] demonstrated a relationship between QRS morphology and inter- and intraventricular delays at phase analysis. In particular, a high intraLV dyssynchrony was associated with LBBB and left axis deviation. In our study, despite the lack of correlation between QRS morphology and degree of mechanical dyssynchrony, LBBB pts showed a significant improvement in biventricular EF compared to RBBB and IVCD pts. Fantoni et al. [21], using a three-dimensional nonfluoroscopic electroanatomic contact mapping system, documented a similar degree of LV activation delay in LBBB and RBBB heart failure pts. However RBBB pts presented also a delayed activation of anterior and lateral RV regions, that was absent in pts with $L B B B$. These data may suggest a more complex electromechanical profile in heart failure RBBB pts, explaining a poor response to CRT and reflecting at the same time the need to identify specific selection criteria. 
Table 5 Baseline clinical characteristics predicting response to CRT

\begin{tabular}{|c|c|c|c|c|}
\hline & Univariate analysis OR $(95 \% \mathrm{Cl})$ & $p$ & Multivariate analysis OR $(95 \% \mathrm{Cl})$ & $p$ \\
\hline Males & $0.36(0.09-1.41)$ & 0.14 & & \\
\hline Age (years) & $1.01(0.96-1.01)$ & 0.63 & & \\
\hline IHD & $0.45(0.13-1.52)$ & 0.20 & & \\
\hline Diabetes & $0.42(0.12-1.49)$ & 0.18 & & \\
\hline Hypertension & $1.18(0.38-3.67)$ & 0.77 & & \\
\hline Chronic kidney disease & $1.41(0.37-5.45)$ & 0.62 & & \\
\hline LBBB & $8.44(2.18-32.66)$ & 0.002 & $7.47(1.80-30.94)$ & 0.006 \\
\hline RBBB & n.a. & n.a. & & \\
\hline Non-specific IVCD & $0.19(0.05-0.74)$ & 0.016 & & \\
\hline QRS duration (ms) & $1.00(0.98-1.02)$ & 0.90 & & \\
\hline QRS $\geq 150 \mathrm{~ms}$ & $1.18(0.38-3.67)$ & 0.77 & & \\
\hline $\mathrm{LBBB}$ and $\mathrm{QRS} \geq 150 \mathrm{~ms}$ & $2.81(0.85-9.28)$ & 0.09 & & \\
\hline Left axis & $0.72(0.23-2.25)$ & 0.57 & & \\
\hline LVEF (\%) & $1.11(1.00-1.23)$ & 0.06 & & \\
\hline RVEF (\%) & $1.01(0.95-1.08)$ & 0.70 & & \\
\hline Intra LV dyssynchrony & $0.28(0.03-2.88)$ & 0.28 & & \\
\hline Intra RV dyssynchrony & $2.11(0.65-6.90)$ & 0.22 & & \\
\hline Interventricular dyssynchrony & $1.52(0.46-5.04)$ & 0.49 & & \\
\hline
\end{tabular}

IHD, ischemic heart disease; LBBB, left bundle branch block; RBBB, right bundle branch block; IVCD, intraventricular conduction disturbance; LVEF, left ventricular ejection fraction; RVEF, right ventricular ejection fraction; LV, left ventricular; RV, right ventricular

Unfortunately, the prevalence of $\mathrm{RBBB}$ and non-specific IVCD is very low in the major CRT randomized trials (about 10\% for RBBB) [4,22], therefore the available data for these groups of pts are limited. In the analysis of pooled data from the MIRACLE and Contak CD trials [23] the LVEF or maximal oxygen consumption did not improve significantly at 6 months follow-up in RBBB pts randomly assigned to CRT. Aldestein et al. [12] evaluated 636 consecutive pts undergoing to CRT implantation with $\mathrm{LBBB}, \mathrm{RBBB}$, or paced QRS at baseline. RBBB pts had low rates of symptomatic and echocardiographic response and the survival free from orthotopic heart transplantation or ventricular assist device placement was significantly worse compared to LBBB pts. In another study of Rickard et al. [24] pts with RBBB and non specificIVCD had less reverse remodeling and symptomatic benefit from CRT compared with those with a native LBBB. Likewise in the CRT-D arm of the MADITCRT trial [25] LBBB pts showed a significantly higher reduction in $L V$ volumes and a significant increase in LVEF compared to non-LBBB pts. Our study is in agreement with these results. Furthermore, we demonstrated that LBBB pts also had a significant improvement in RVEF (although the magnitude of the response was less than for LVEF), whereas pts with non-LBBB had no significant improvement in RVEF. The mechanisms by which LBBB pattern promotes improvement in RVEF in response to CRT are unclear [26], but may result in part from a reduction in right ventricular afterload with improvement in left-sided pump function.

\section{Study limitations}

The small RBBB sample size was the main limitation of our study, reducing the statistical value of results for this specific group of pts. However, as previously reported, the low prevalence of $\mathrm{RBBB}$ candidates to CRT reflects a common condition encountered in clinical practice as well as in most trials during pts selection for CRT. In this context, further prospective studies are needed to investigate the relationship between electromechanical dyssynchrony and CRT response in RBBB pts in order to improve pts selection and optimize the device system capabilities in these pts.

\section{Conclusion}

In this prospective study we evaluated the relationship between QRS pattern, mechanical dyssynchrony and CRT response. $\mathrm{LBBB}$ is a significant marker of a positive response to CRT, irrespective of QRS duration, in terms of improvement not only in LVEF but also in RVEF. Pts with non-LBBB pattern seem to benefit less from CRT than those with LBBB. Further evaluations to clarify the mechanisms allowing RVEF improvement in LBBB pts are required.

\section{Author details}

${ }^{1}$ Institute of Cardiology, University of Bologna, Via Massarenti 9, Bologna 40138, Italy. ${ }^{2}$ Cardiology Service, University Hospital of Geneva, Geneva, 
Switzerland. ${ }^{3}$ Department of Nuclear Medicine, S. Orsola-Malpighi Hospital, Bologna, Italy.

\section{Authors' contributions}

GD: data collection, data analysis/interpretation, statistics, drafting article. HB: concept/design, data analysis/interpretation, drafting article, critical revision of article, approval of article. CV: data collection, data analysis/interpretation. GG: data collection, data analysis/interpretation. FF: data collection, data analysis/interpretation. MB: data collection, data analysis/interpretation. HS: data collection, data analysis/interpretation. ID: data collection, data analysis/ interpretation. CM: data collection, data analysis/interpretation. HF: data collection. EF: data collection. GB: concept/design, data analysis/ interpretation, drafting article, critical revision of article, approval of article. All authors read and approved the final manuscript.

\section{Competing interests}

The authors declare that they have no competing interests.

Received: 20 October 2011 Accepted: 11 April 2012

Published: 11 April 2012

\section{References}

1. Cazeau S, Leclercq C, Lavergne T, Walker S, Varma C, Linde C, Garrigue S, Kappenberger L, Haywood GA, Santini M, Bailleul C, Daubert JC: Effects of multisite biventricular pacing in patients with heart failure and intraventricular conduction delay. N Engl J Med 2001, 344:873-880.

2. Linde C, Leclerca C, Rex S, Garrigue S, Lavergne T, Cazeau S, McKenna W, Fitzgerald M, Deharo JC, Alonso C, Walker S, Braunschweig F, Bailleul C, Daubert JC: Long-term benefits of biventricular pacing in congestive heart failure: results from the MUltisite STimulation in cardiomyopathy (MUSTIC) study. J Am Coll Cardiol 2002, 40:111-118.

3. Abraham WT, Fisher WG, Smith AL, Delurgio DB, Leon AR, Loh E, Kocovic DZ, Packer M, Clavell AL, Hayes DL, Ellestad M, Trupp RJ, Underwood J, Pickering F, Truex C, McAtee P, Messenger J: Cardiac resynchronization in chronic heart failure. N Engl J Med 2002, 346:1845-1853

4. Bristow MR, Saxon LA, Boehmer J, Krueger S, Kass DA, De Marco T, Carson P, DiCarlo L, DeMets D, White BG, DeVries DW, Feldman AM: Cardiac-resynchronization therapy with or without an implantable defibrillator in advanced chronic heart failure. N Engl J Med 2004, 350:2140-2150.

5. Cleland JG, Daubert JC, Erdmann E, Freemantle N, Gras D, Kappenberger L, Tavazzi L: The effect of cardiac resynchronization on morbidity and mortality in heart failure. N Engl J Med 2005, 352:1539-1549.

6. St-John-Sutton MG, Plappert T, Abraham WT, Smith AL, DeLurgio DB, Leon AR, Loh E, Kocovic DZ, Fisher WG, Ellestad M, Messenger J, Kruger K, Hilpisch KE, Hill MR: Effect of cardiac resynchronization therapy on left ventricular size and function in chronic heart failure. Circulation 2003, 107:1985-1990.

7. Cleland JG, Daubert JC, Erdmann E, Freemantle N, Gras D, Kappenberger L, Tavazzi L: Longer-term effects of cardiac resynchronization therapy on mortality in heart failure [the CArdiac REsynchronization-Heart Failure (CARE-HF) trial extension phase]. Eur Heart J 2006, 27:1928-1932.

8. Yu CM, Fung WH, Lin H, Zhang Q, Sanderson JE, Lau CP: Predictors of left ventricular reverse remodeling after cardiac resynchronization therapy for heart failure secondary to idiopathic dilated or ischemic cardiomyopathy. Am J Cardiol 2003, 91:684-688.

9. Dickstein K, Vardas PE, Auricchio A, Daubert JC, Linde C, McMurray J, Ponikowski P, Priori SG, Sutton R, van Veldhuisen DJ, Vahanian A, Bax J, Ceconi C, Dean V, Filippatos G, Funck-Brentano C, Hobbs R, Kearney P, McDonagh T, Popescu BA, Reiner Z, Sechtem U, Sirnes PA, Tendera M, Vardas P, Widimsky P, Anker SD, Blanc JJ, Gasparini M, Hoes AW, Israel CW, Kalarus Z, Merkely B, Swedberg K, Camm AJ: 2010 Focused Update of ESC Guidelines on device therapy in heart failure: an update of the 2008 ESC Guidelines for the diagnosis and treatment of acute and chronic heart failure and the 2007 ESC guidelines for cardiac and resynchronization therapy. Developed with the special contribution of the Heart Failure Association and the European Heart Rhythm Association. Eur Heart J 2010, 31:2677-2687.

10. Epstein AE, DiMarco JP, Ellenbogen KA, Estes NA, Freedman RA, Gettes LS, Gillinov AM, Gregoratos G, Hammill SC, Hayes DL, Hlatky MA, Newby LK,
Page RL, Schoenfeld MH, Silka MJ, Stevenson LW, Sweeney MO, Smith SC Jr, Jacobs AK, Adams CD, Anderson JL, Buller CE, Creager MA, Ettinger SM, Faxon DP, Halperin JL, Hiratzka LF, Hunt SA, Krumholz HM, Kushner FG, Lytle BW, Nishimura RA, Ornato JP, Riegel B, Tarkington LG, Yancy CW: ACC/ AHA/HRS 2008 Guidelines for Device-Based Therapy of Cardiac Rhythm Abnormalities: a report of the American College of Cardiology/American Heart Association Task Force on Practice Guidelines (Writing Committee to Revise the ACC/AHA/NASPE 2002 Guideline Update for Implantation of Cardiac Pacemakers and Antiarrhythmia Devices) developed in collaboration with the American Association for Thoracic Surgery and Society of Thoracic Surgeons. J Am Coll Cardiol 2008, 51:e1-62.

11. Gervais R, Leclercq C, Shankar A, Jacobs S, Eiskjaer H, Johannessen A, Freemantle N, Cleland JG, Tavazzi L, Daubert C: Surface electrocardiogram to predict outcome in candidates for cardiac resynchronization therapy: a sub-analysis of the CARE-HF trial. Eur I Heart Fail 2009, 11:699-705.

12. Adelstein EC, Saba S: Usefulness of baseline electrocardiographic QRS complex pattern to predict response to cardiac resynchronization. Am J Cardiol 2009, 103:238-242.

13. Tang AS, Wells GA, Talajic M, Arnold MO, Sheldon R, Connolly S, Hohnloser SH, Nichol G, Birnie DH, Sapp JL, Yee R, Healey JS, Rouleau JL: Cardiac-resynchronization therapy for mild-to-moderate heart failure. $N$ Engl J Med 2010, 363:2385-2395.

14. Barsheshet A, Goldenberg I, Moss AJ, Eldar M, Huang DT, McNitt S, Klein HU, Hall WJ, Brown MW, Goldberger JJ, Goldstein RE, Schuger C, Zareba W, Daubert JP: Response to preventive cardiac resynchronization therapy in patients with ischaemic and nonischaemic cardiomyopathy in MADIT-CRT. Eur Heart J 2011, 32:1622-1630.

15. Surawicz B, Childers R, Deal BJ, Gettes LS, Bailey JJ, Gorgels A, Hancock EW, Josephson M, Kligfield P, Kors JA, Macfarlane P, Mason JW, Mirvis DM, Okin P, Pahlm O, Rautaharju PM, van Herpen G, Wagner GS, Wellens H: AHA/ACCF/HRS recommendations for the standardization and interpretation of the electrocardiogram: part III: intraventricular conduction disturbances: a scientific statement from the American Heart Association Electrocardiography and Arrhythmias Committee, Council on Clinical Cardiology; the American College of Cardiology Foundation; and the Heart Rhythm Society: endorsed by the International Society for Computerized Electrocardiology. Circulation 2009, 119:e235-240.

16. Bax JJ, Marwick TH, Molhoek SG, Bleeker GB, van Erven L, Boersma E, Steendijk P, van der Wall EE, Schalij MJ: Left ventricular dyssynchrony predicts benefit of cardiac resynchronization therapy in patients with end-stage heart failure before pacemaker implantation. Am J Cardiol 2003, 92:1238-1240.

17. Boriani G, Fallani F, Martignani C, Biffi M, Saporito D, Greco C, Ziacchi M, Levorato M, Pontone G, Valzania C, Diemberger I, Franchi R, Branzi A: Cardiac resynchronization therapy: effects on left and right ventricular ejection fraction during exercise. Pacing Clin Electrophysiol 2005, 28(Suppl 1):11-14.

18. Burri H, Sunthorn H, Somsen A, Zaza S, Fleury E, Shah D, Righetti A: Optimizing sequential biventricular pacing using radionuclide ventriculography. Heart Rhythm 2005, 2:960-965.

19. Fauchier L, Marie O, Casset-Senon D, Babuty D, Cosnay P, Fauchier JP: Interventricular and intraventricular dyssynchrony in idiopathic dilated cardiomyopathy: a prognostic study with fourier phase analysis of radionuclide angioscintigraphy. J Am Coll Cardiol 2002, 40:2022-2030

20. Fauchier L, Marie O, Casset-Senon D, Babuty D, Cosnay P, Fauchier JP: Reliability of QRS duration and morphology on surface electrocardiogram to identify ventricular dyssynchrony in patients with idiopathic dilated cardiomyopathy. Am J Cardiol 2003, 92:341-344.

21. Fantoni C, Kawabata M, Massaro R, Regoli F, Raffa S, Arora V, SalernoUriarte $\mathrm{JA}$, Klein $\mathrm{HU}$, Auricchio A: Right and left ventricular activation sequence in patients with heart failure and right bundle branch block: a detailed analysis using three-dimensional non-fluoroscopic electroanatomic mapping system. J Cardiovasc Electrophysiol 2005, 16:112-119, discussion 120-121.

22. Moss AJ, Hall WJ, Cannom DS, Klein H, Brown MW, Daubert JP, Estes NA, Foster E, Greenberg H, Higgins SL, Pfeffer MA, Solomon SD, Wilber D, Zareba W: Cardiac-resynchronization therapy for the prevention of heartfailure events. N Engl J Med 2009, 361:1329-1338.

23. Egoavil CA, Ho RT, Greenspon AJ, Pavri BB: Cardiac resynchronization therapy in patients with right bundle branch block: analysis of pooled 
data from the MIRACLE and Contak CD trials. Heart Rhythm 2005, 2:611-615.

24. Rickard J, Kumbhani DJ, Gorodeski EZ, Baranowski B, Wazni O, Martin DO, Grimm R, Wilkoff BL: Cardiac resynchronization therapy in non-left bundle branch block morphologies. Pacing Clin Electrophysiol 2010, 33:590-595.

25. Zareba W, Klein H, Cygankiewicz I, Hall WJ, McNitt S, Brown M, Cannom D, Daubert JP, Eldar M, Gold MR, Goldberger JJ, Goldenberg I, Lichstein E, Pitschner H, Rashtian M, Solomon S, Viskin S, Wang P, Moss AJ:

Effectiveness of Cardiac Resynchronization Therapy by QRS Morphology in the Multicenter Automatic Defibrillator Implantation Trial-Cardiac Resynchronization Therapy (MADIT-CRT). Circulation 2011, 123:1061-1072.

26. Burri H, Domenichini G, Sunthorn H, Fleury E, Stettler C, Foulkes I, Shah D: Right ventricular systolic function and cardiac resynchronization therapy Europace 2010, 12:389-394.

\section{Pre-publication history}

The pre-publication history for this paper can be accessed here: http://www.biomedcentral.com/1471-2261/12/27/prepub

doi:10.1186/1471-2261-12-27

Cite this article as: Domenichini et al:: QRS pattern and improvement in right and left ventricular function after cardiac resynchronization

therapy: a radionuclide study. BMC Cardiovascular Disorders 2012 12:27.

\section{Submit your next manuscript to BioMed Central} and take full advantage of:

- Convenient online submission

- Thorough peer review

- No space constraints or color figure charges

- Immediate publication on acceptance

- Inclusion in PubMed, CAS, Scopus and Google Scholar

- Research which is freely available for redistribution

Submit your manuscript at www.biomedcentral.com/submit 